\title{
New species and records of Afrotropical, Oriental and Palaearctic Venturia Schrottky, 1902 (Hymenoptera: Ichneumonidae: Campopleginae)
}

\author{
Z. VAS \\ Zoltán Vas, Hungarian Natural History Museum, Department of Zoology, Hymenoptera Collection, H-1088 \\ Budapest, Baross u. 13., Hungary.E-mail: vas.zoltan@nhmus.hu
}

\begin{abstract}
Five new species of Venturia Schrottky, 1902 are described from the Afrotropical and Oriental regions, Venturia aurantia sp. nov. from South Africa, Venturia erythrina sp. nov. from Tanzania, Venturia ignea sp. nov. from Ghana, Venturia veruta sp. nov. from Uganda, and Venturia biroi sp. nov. from India. The hitherto unknown male sex of Venturia peringueyi (Cameron, 1906), a South African species, is also described. Additionally, the first records of Venturia aquila Vas, 2019 and Venturia crassicaput (Morley, 1926) from South Africa, and Venturia canescens (Gravenhorst, 1829) from Cyprus, Crete and Tanzania are given.
\end{abstract}

Keywords. ichneumon wasp, species description, distribution, Old World.

\section{INTRODUCTION}

$V$ enturia Schrottky, 1902 is a species-rich genus of family Ichneumonidae, subfamily Campopleginae. Prior to this study 138 valid species were known worldwide; 44 of them occur in the Neotropical, 40 in the Nearctic, 35 in the Oriental, 11 in the Afrotropical, 8 in the Western Palaearctic, 8 in the Eastern Palaearctic, 4 in the Australasian, and 4 in the Oceanic regions ( $\mathrm{Yu}$ et al. 2012, Vas 2019a,b).

In this paper, based on the material of the Hungarian Natural History Museum (HNHM, Budapest) and the Biological Museum of Lund University (MZLU, Lund), five new species of the genus are described (four species from the Afrotropical region and one species from the Oriental region), the hitherto unknown male sex of Venturia peringueyi (Cameron, 1906), a South African species, is also described, and new distributional records of some Venturia species are given.

\section{MATERIAL AND METHODS}

Taxonomy and nomenclature follow $\mathrm{Yu} \&$ Horstmann (1997) and $\mathrm{Yu}$ et al. (2012); hence, complete nomenclatural history and list of synonym taxa are not repeated here. The morphological terminology is primarily based on Gauld (1991) and Gauld et al. (1997); however, in some cases, especially regarding wing veins, the corresponding terminology of Townes (1969) is also indicated. In the case of Oriental species, for better comparability with Gupta \& Maheshwary (1977), both the length of ovipositor sheath and the total length of exposed ovipositor are given. The identifications were based on Gravenhorst (1829), Förster (1869), Magretti (1884), Schrottky (1902), Cameron (1906, 1912), Enderlein (1914), Morley (1926), Seyrig (1935), Townes et al. (1961), Momoi (1965), Townes (1970), Horstmann (1973), Townes \& Townes (1973), Gupta \& Maheshwary (1977), Horstmann (1979), Wahl (1987), Kusigemati (1988), Polaszek et al. (1994), Zwart (1998), Jonathan (1999), Sudheer \& Nar- 
endran (2006), Horstmann (2008), van Noort (2019), Vas $(2019 a, b)$, and on checking the relevant type material (i.e. type specimens of all species listed in the taxonomy section were examined at least by digital images except that of Venturia canescens (Gravenhorst, 1829) which type material was unnecessary to check), and specimens determined by V.K. Gupta in HNHM. The specimens were identified and examined by the author using a Nikon SMZ645 stereoscopic microscope. Results are grouped into biogeographical regions, within biogeographical regions species are listed alphabetically. Label data is given as is, with clarifying, abbreviated or missing information given in brackets. Photos were taken with a 14 MP MicroQ-U3L digital camera. Post image work was done with ToupTek ToupView v4.7 and Photoshop CS3.

\section{TAXONOMY AND RESULTS}

\section{Subfamily: Campopleginae Förster, 1869 \\ Genus: Venturia Schrottky, 1902}

Type species: Venturia argentina Schrottky; designation by Viereck (1914).

\section{AFROTROPICAL REGION}

Before this study, 11 valid species were known from the region (Yu et al. 2012, Vas 2019a). Most Afrotropical species were described several decades ago (Yu et al. 2012), except quite recently a new species, Venturia aquila Vas, 2019 was described from Ghana, along with the unknown female sex of Venturia crassicaput (Morley, 1926) (Vas 2019a). With the new species described below, the number of Afrotropical Venturia species increased to 15 .

\section{Venturia aquila Vas, 2019}

Material examined. Two females, S. Afr. [= South Africa], Cape Prov., Cape Peninsula, Hout Bay, Skoorsteenkop, 26.XII.[19]50, leg. Brinck \& Rudenbeck, Swedish South African Expedition 1950-1951, No. 95, Insect trap, Id. No. MZLUHYM 26390, 26397. - Two females, same locality, collectors, 22.I.[19]51, No. 157, Id. No. MZLU-HYM 26385, 26388. - One female, same locality, collectors, 2.II.[19]51, No. 166, Id. No. MZLU-HYM 26384. - One female, same locality, collectors, 14.II.[19]51, No. 183, Id. No. MZLUHYM 26399. - The specimens are deposited in MZLU (Lund) except MZLU-HYM 26385, 26397 are deposited in HNHM (Budapest) (HNHMHYM 154982, 154983).

Remarks. First records for South Africa. This species was recently described from Ghana (Vas 2019a). As compared to the holotype specimen of this species, the following slight intraspecific variations were observed: tegula yellow to yellowish brown, middle legs entirely blackish to dark brown.

\section{Venturia aurantia sp. nov.}

(Figures 1-3)

Material examined. Holotype: female, S. Afr. [= South Africa], Cape Prov., Cape Peninsula, Hout Bay, Skoorsteenkop, 22.I.[19]51, leg. Brinck \& Rudenbeck, Swedish South African Expedition 1950-1951, No. 157, Insect trap; specimen pinned, Id. No. MZLU-HYM 26382. Paratypes: three females, same locality, date, collector; specimens pinned, Id. No. MZLU-HYM 26383, 26396, 26398; one female and one male, same locality, collector, 2.II.[19]51, No. 166; specimens pinned, Id. No. MZLU-HYM 26389 (male, antennae missing), 26393. - The holotype and three paratype specimens (MZLU-HYM 26383, 26389, 26393) are deposited in MZLU (Lund), two paratype specimens (MZLU-HYM 26396, 26398) are deposited in HNHM (Budapest) (HNHM-HYM 154986, 154987).

Diagnosis. Among the Afrotropical species of the genus, Venturia aurantia sp. nov. could be reliably identified by the combined presence of the following characters: gena in dorsal view 0.4 $0.5 \times$ as long as eye width, moderately strongly narrowed behind eye, mesopleuron punctate on granulate background, ventral part of epicnemial carina little elevated, posterior transverse carina of mesosternum elevated, medially distinctly 
excised and curved inwards, submedially convex, area superomedia relatively short and wide, $c a$ $1.6 \times$ as long as wide, area superomedia and area petiolaris with distinct transverse wrinkles, propodeal carinae complete, lateromedian longitudinal carinae distinctly angulate at costulae and convergent behind costulae, areolet long-stalked, ovipositor sheath $1.2-1.4 \times$ as long as hind tibia, ovipositor evenly, weakly upcurved, scapus and pedicellus ventrally more or less extensively orange brown, mandible yellow except teeth, tegula orange brown, basal three tergites of metasoma predominantly dark, following tergites extensively reddish, fore coxa orange, middle coxa dark brown, apically narrowly orange brown, hind coxa blackish, apically very narrowly orange brown, rest of legs entirely to almost entirely reddish orange.

Description. Female (Figs 1-3). Body length ca 7-8 mm, fore wing length $c a 5 \mathrm{~mm}$.

Head. Antenna with 35-37 flagellomeres; first flagellomere long and slender, 3.5-3.9× as long as wide apically; preapical flagellomeres quadrate to slightly longer than wide. Head transverse, matt, with dense, short, greyish hairs. Ocular-ocellar distance $0.8-0.9 \times$ as long as ocellus diameter, posterior ocellar distance $1.5-1.7 \times$ as long as ocellus diameter, posterior ocellar distance 1.6$1.8 \times$ as long as ocular-ocellar distance. Inner eye orbits slightly indented, about parallel. Gena granulate with dense, superficial punctures, moderately short, in dorsal view $0.4-0.5 \times$ as long as eye width, moderately strongly narrowed behind eye. Occipital carina complete, medially evenly arched, reaching hypostomal carina little before base of mandible, hypostomal carina slightly elevated. Frons flat, without median longitudinal carina, rugose-punctate. Face very weakly convex in profile, rugose-punctate. Clypeus rugosepunctate, very weakly separated from face, flat in profile, relatively wide, its apical margin very weakly convex, sharp. Malar space $0.5 \times$ as long as basal width of mandible. Mandible relatively long, lower margin of mandible with a wide flange from base toward teeth, flange gradually narrowed toward teeth, mandibular teeth of equal length.
Mesosoma. Mesosoma with dense, short, greyish hairs. Pronotum rugose-punctate, ventral half to two-third with strong transverse wrinkles on predominantly smooth background; epomia strong. Mesoscutum rugose-punctate, convex in profile, $c a 1.1 \times$ as long as wide, notaulus not developed. Scuto-scutellar groove wide, deep. Scutellum rugose-punctate, convex, lateral carina indistinct. Upper half of mesopleuron densely punctate with weak rugosity, lower half densely punctate on granulate background, distances between punctures smaller than puncture diameters, with rather strong transverse wrinkles above and anterior to speculum; speculum smooth, shiny; mesopleural suture impressed with short, relatively strong transverse costae. Epicnemial carina complete, strong, pleural part bent to anterior margin of mesopleuron reaching it below its middle height, transversal part (i.e. part at the level of sternaulus running through the epicnemium to the ventral edge of pronotum) not developed, ventral part (behind fore coxae) complete, little elevated. Sternaulus indistinct. Posterior transverse carina of mesosternum complete, elevated, medially distinctly excised and curved inwards, submedially convex. Metanotum rugose-punctate, $0.4-0.5 \times$ as long as scutellum. Metapleuron rugose-punctate; juxtacoxal carina indistinct; submetapleural carina complete, strong. Pleural carina of propodeum strong; propodeal spiracle oval, separated from pleural carina by $c a$ $0.5-0.7 \times$ its length, connected to pleural carina by a weak ridge. Propodeum long, its apex reaching middle length of hind coxa, coarsely rugosepunctate, area superomedia and area petiolaris with distinct transverse wrinkles and rugosity, medially not impressed. Area basalis trapezoidal, rather short, $c a 0.5 \times$ as long as its basal width; area superomedia hexagonal, relatively short and moderately wide, $\mathrm{ca} 1.6 \times$ as long as wide, reaching up to basal $0.40-0.45 \times$ length of propodeum, apically opened, confluent with area petiolaris; area petiolaris moderately wide. Propodeal carinae complete; lateromedian longitudinal carinae distinctly angulate at costulae and convergent behind costulae. Fore wing with longstalked areolet, its stalk $0.7-0.9 \times$ as long as maximum height of areolet, $3 r s-m$ present, 
pigmented, second recurrent vein $(2 m-c u)$ close to distal corner of areolet; distal abscissa of $R s$ straight; nervulus $(\mathrm{cu}-a)$ interstitial to slightly postfurcal, weakly inclivous; postnervulus (abscissa of $C u 1$ between $1 m-c u$ and $C u 1 \mathrm{a}+C u 1 b)$ intercepted slightly above its middle by $\mathrm{Cu} 1 \mathrm{a}$; lower external angle of second discal cell acute. Hind wing with nervellus ( $c u-a+$ abscissa of $C u 1$ between $M$ and $c u-a$ ) broken, intercepted by discoidella (distal abscissa of $C u 1$ ) at about posterior $0.2-0.3 \times$ its length, strongly inclivous above discoidella, weakly reclivous below discoidella; discoidella spectral, proximally connected to nervellus. Coxae granulate with weak punctures. Hind femur relatively stout, $c a$ $5 \times$ as long as high. Inner spur of hind tibia $c a$ $0.5 \times$ as long as first tarsomere of hind tarsus. Tarsal claws slightly longer than arolium, basal two-third with strong pecten.

Metasoma. Metasoma with short, greyish to light brownish hairs, compressed, petiolus smooth, from postpetiolus finely granulate to shagreened. First tergite $c a 4.6-4.8 \times$ as long as width of its apical margin, $1.1-1.2 \times$ as long as second tergite, $\mathrm{ca} 0.95 \times$ as long as hind femur, without glymma; dorsomedian carina of first tergite missing; postpetiolus bulging. Suture separating first tergite from first sternite situated little above mid-height at basal third of first metasomal segment. Second tergite long and slender, $c a$ 1.8$2.1 \times$ as long as its apical width; thyridium small, oval, its distance from basal margin of tergite $c a$ $3 \times$ as long as its length, not connected to basal margin of tergite by a groove. Posterior margins of apical tergites medially distinctly excised. Ovipositor sheath $1.2-1.4 \times$ as long as hind tibia; ovipositor compressed, evenly, weakly upcurved.

Colour. Antenna dark brown, scapus and pedicellus ventrally more or less extensively orange brown. Head black except palpi and mandible yellow, mandibular teeth dark reddish brown. Mesosoma black except tegula orange brown. Metasoma: first tergite black, postpetiolus laterally and apically very dark reddish brown; second tergite blackish, apical margin and apicolateral corners narrowly reddish brown; third tergite blackish to dark brown, subapically widely reddish, apically narrowly dark brown, sometimes less extensively reddish; following tergites reddish with dark brown dorsal patches; ovipositor sheath blackish. Wings hyaline, wing veins and pterostigma brown. Fore leg: entirely reddish orange, apical tarsomere darkened. Middle leg: coxa dark brown, apically narrowly orange brown; rest of leg reddish orange, apical tarsomere darkened. Hind leg: coxa blackish, apically very narrowly orange brown; rest of leg reddish orange, except tibia dorsally and tarsus more or less darkened, brownish, rarely trochanter partly brownish.

Male. Similar to female in all characters described above, except: propodeal spiracle elongate oval, separated from pleural carina by $c a$ about its length, connected to pleural carina by a strong ridge; propodeal carinae and sculpture stronger than in female; stalk of areolet little shorter than in female; first tergite slenderer, $c a 5.5 \times$ as long as width of its apical margin, $1.3 \times$ as long as second tergite; third and following tergites short, posterior margins medially not excised; claspers narrowly, deeply notched dorsally; first tergite entirely, second and third tergites almost entirely black, dorsal patches of apical tergites larger and darker than in female; wings subhyaline.

\section{Distribution. South Africa.}

Etymology. The specific epithet aurantia is the feminine form of the Latin adjective aurantius, $-a$, -um meaning orange-coloured; it refers to the colouration of legs of the new species.

Remarks. The new species is similar to Venturia canescens (Gravenhorst, 1829), which could be distinguished from the new species by its following characteristics: gena shorter (in dorsal view $c a 0.3 \times$ as long as eye width) and more strongly narrowed behind eye, background of mesopleuron somewhat smoother, more finely sculptured, posterior transverse carina of mesosternum normal, area superomedia much more elongate and narrow ( $\mathrm{ca} 2 \times$ as long as wide), lateromedian longitudinal carinae about parallel and not distinctly angulate at costulae, areolet 

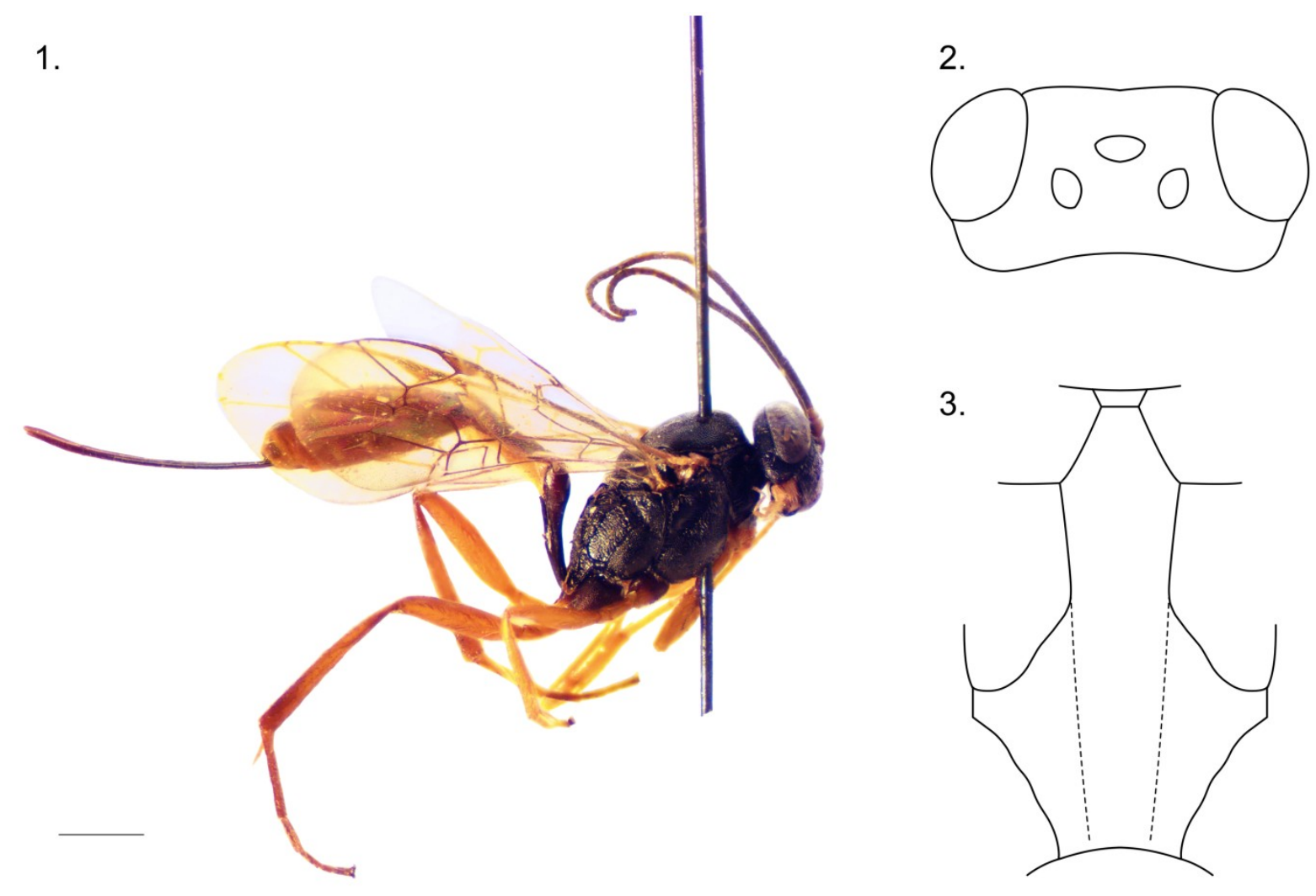

Figures 1-3. Venturia aurantia sp. nov. $1=$ holotype, lateral habitus (scale bar $=1 \mathrm{~mm}) ; 2=$ head, dorsal view; $3=$ shape of median areas of propodeum.

short-stalked or subsessile, ovipositor sheath longer, $\mathrm{ca} 1.6 \times$ as long as hind tibia, male claspers more widely and less deeply notched dorsally, tegula yellow, fore and middle coxae, trochanters, trochantelli, and hind trochantellus yellowish, femora and tibiae mostly yellowish brown to brownish, not orange.

\section{Venturia canescens (Gravenhorst, 1829)}

Material examined. Three females and one male, Tanzania, Usa River, 1190m, 1965, leg. J. Szunyoghy, Id. No. HNHM-HYM 154976154979. - The specimens are deposited in HNHM (Budapest).

Remarks. First record for Tanzania. This species has a worldwide distribution ( $\mathrm{Yu}$ et al. 2012, Vas 2019a).

\section{Venturia crassicaput (Morley, 1926)}

Material examined. One female, S. Afr. [= South Africa], Natal, Royal Natal National Park, Tugela Valley, 5.IV.[19]51, leg. Brinck \& Rudenbeck, Swedish South African Expedition 19501951, No. 265, Insect trap, Id. No. MZLU-HYM 26380. - Four females and one male, S. Afr. [= South Africa], Natal, Royal Natal National Park, 7-11.IV.[19]51, same collectors, No. 271, Id. No. MZLU-HYM 26379, 26381 (male), 26386, 26387, 26401. - The specimens are deposited in MZLU (Lund) except MZLU-HYM 26387, 26401 are deposited in HNHM (Budapest) (HNHMHYM 154984, 154985).

Remarks. First records for South Africa. This species was described from Zimbabwe and recently reported from Tanzania ( $\mathrm{Yu}$ et al. 2012, Vas 2019a). 


\section{Venturia erythrina sp. nov.}

\author{
(Figures 4-6)
}

Material examined. Holotype: female, Africa or. [= orientalis], [Tanzania], Arusha, 1906, leg. [K.] Katona $[=\mathrm{K}$. Kittenberger $]$; specimen pinned, Id. No. HNHM-HYM 154972. - The holotype specimen is deposited in HNHM (Budapest).

Diagnosis. Among the Afrotropical species of the genus, Venturia erythrina sp. nov. could be reliably identified by the combined presence of the following characters: gena long, in dorsal view $0.7 \times$ as long as eye width, subparallel behind eye, area superomedia moderately narrow, $1.6 \times$ as long as wide, ovipositor sheath $2.4 \times$ as long as hind tibia, ovipositor tip strongly upcurved, scapus ventrally brownish yellow, mandible yellowish except teeth, tegula light reddish brown, metasoma rusty reddish except basal 0.4 of first tergite black and extreme base of second tergite very narrowly blackish, all legs, including coxae, reddish to rusty reddish, except middle and hind tibiae dorsally brownish, basal 0.2 of hind tibia dark brown, middle and hind tarsi brown.

Description. Female (Figs 4-6). Body length ca $10 \mathrm{~mm}$, fore wing length $c a 7 \mathrm{~mm}$.

Head. Antenna with 42 flagellomeres; first flagellomere $c a 3 \times$ as long as wide apically; preapical flagellomeres longer than wide. Head transverse, matt, with dense, short, silvery hairs. Ocular-ocellar distance $0.9 \times$ as long as ocellus diameter, posterior ocellar distance $1.2 \times$ as long as ocellus diameter, posterior ocellar distance $1.3 \times$ as long as ocular-ocellar distance. Inner eye orbits slightly indented, about parallel. Gena distinctly, densely punctate on granulate surface, moderately buccate, long, in dorsal view $0.7 \times$ as long as eye width, subparallel behind eye. Occipital carina complete, medially evenly arched, reaching hypostomal carina distinctly before base of mandible, hypostomal carina not elevated. Frons flat, without median longitudinal carina, rugose-punctate. Face almost flat in profile, densely rugose-punctate. Clypeus weakly rugose with dense punctures, very weakly separated from face, flat in profile, relatively wide, its apical margin almost straight, sharp. Malar space short, $0.4 \times$ as long as basal width of mandible. Mandible moderately long, lower margin of mandible with moderately wide flange from base toward teeth, flange gradually narrowed toward teeth, mandibular teeth of equal length.

Mesosoma. Mesosoma with dense, short, silvery hairs. Pronotum strongly and densely rugose-punctate, ventral half with weak transverse wrinkles; epomia distinct. Mesoscutum coarsely rugose-punctate, convex in profile, about as long as wide, notaulus not developed. Scuto-scutellar groove wide, deep. Scutellum rugose-punctate, convex, lateral carina indistinct. Upper half of mesopleuron moderately rugose with strong, dense punctures, lower half strongly, densely punctate on coarsely granulate background, distances between punctures smaller than puncture diameters, with weak transverse wrinkles anterior to speculum; speculum relatively small, very finely granulate to smooth, shiny; mesopleural suture impressed with short, relatively weak transverse costae. Epicnemial carina complete, strong, pleural part bent to anterior margin of mesopleuron reaching it below its middle height, transversal part (i.e. part at the level of sternaulus running through the epicnemium to the ventral edge of pronotum) not developed, ventral part (behind fore coxae) complete, slightly elevated. Sternaulus indistinct. Posterior transverse carina of mesosternum complete, little elevated, medially not excised. Metanotum rugose-punctate, ca $0.5 \times$ as long as scutellum. Metapleuron rugosepunctate; juxtacoxal carina indistinct; submetapleural carina complete, strong. Pleural carina of propodeum strong; propodeal spiracle elongate oval, separated from pleural carina by $c a 0.5 \times$ its length, connected to pleural carina by a weak ridge. Propodeum long, its apex reaching middle length of hind coxa, coarsely and densely rugosepunctate, except area superomedia granulate with relatively weak transverse wrinkles and area petiolaris with mostly transverse rugosity, medially not impressed. Area basalis trapezoidal, small, about as long as its basal width; area superomedia elongate hexagonal, moderately narrow, $1.6 \times$ as long as wide, reaching up to basal $0.35 \times$ length of propodeum, behind costulae 

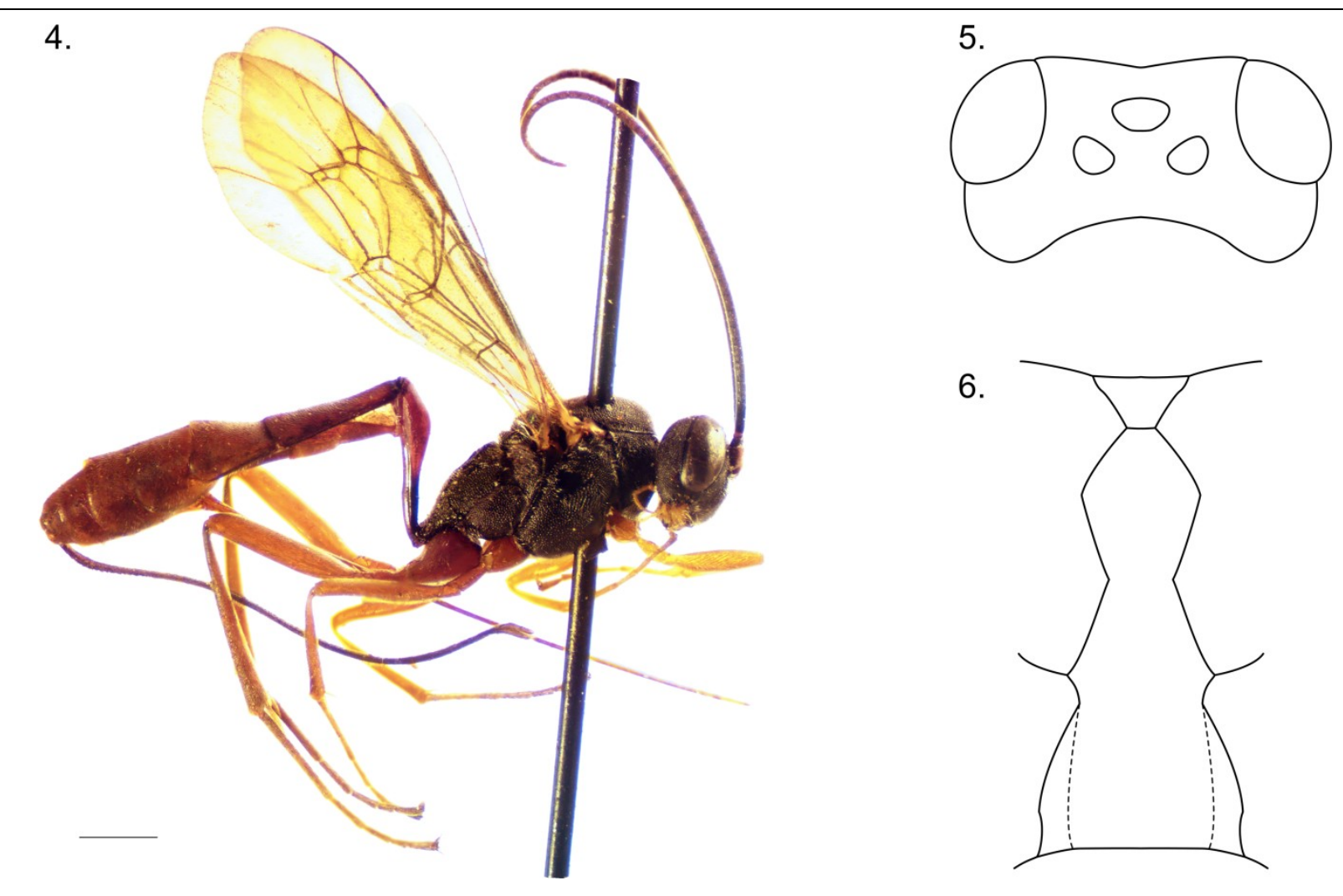

6.

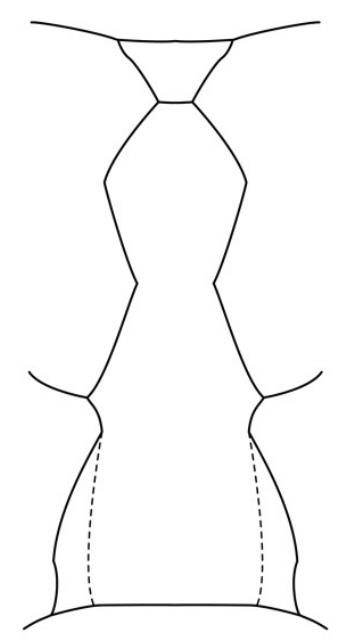

Figures 4-6. Venturia erythrina sp. nov. $1=$ holotype, lateral habitus (scale bar $=1 \mathrm{~mm}) ; 2=$ head, dorsal view; $3=$ shape of median areas of propodeum.

distinctly constricted; area petiolaris moderately narrow. Propodeal carinae strongly developed, area superomedia apically opened, confluent with area petiolaris. Fore wing with short-stalked, relatively large areolet, its stalk about $0.25 \times$ as long as maximum height of areolet, $3 r s-m$ present, pigmented, second recurrent vein $(2 m-c u)$ little to distal middle of areolet; distal abscissa of $R s$ almost straight, distally weakly curved toward wing margin; nervulus (cu-a) interstitial, strongly inclivous; postnervulus (abscissa of $\mathrm{Cu} 1$ between $1 m-c u$ and $C u 1 \mathrm{a}+C u 1 b)$ intercepted slightly above its middle by $\mathrm{Cu} 1 \mathrm{a}$; lower external angle of second discal cell acute. Hind wing with nervellus (cu-a + abscissa of $C u 1$ between $M$ and $c u-a$ ) weakly broken, intercepted by discoidella (distal abscissa of $\mathrm{Cu}$ ) at about posterior $0.3 \times$ its length, vertical above discoidella, weakly reclivous below discoidella; discoidella spectral, proximally connected to nervellus. Coxae granulate with distinct, dense punctures. Hind femur relatively stout, $c a$ $5 \times$ as long as high. Inner spur of hind tibia $c a$
$0.5 \times$ as long as first tarsomere of hind tarsus. Tarsal claws strong, distinctly longer than arolium, basal half with strong pecten.

Metasoma. Metasoma with short, greyish hairs, moderately compressed, petiolus smooth, from postpetiolus finely granulate to shagreened. First tergite $\mathrm{ca} 4 \times$ as long as width of its apical margin, $1.1 \times$ as long as second tergite, $0.95 \times$ as long as hind femur, without glymma; dorsomedian carina of first tergite missing; postpetiolus bulging. Suture separating first tergite from first sternite situated at about mid-height at basal third of first metasomal segment. Second tergite long and slender, $\mathrm{ca} 2 \times$ as long as its apical width; thyridium small, oval, weak, its distance from basal margin of tergite $c a 3 \times$ as long as its length, not connected to basal margin of tergite by a groove. Posterior margins of third and following tergites medially distinctly, widely concave. Ovipositor sheath $2.4 \times$ as long as hind tibia; ovipositor compressed, shaft weakly, tip strongly upcurved. 
Colour. Antenna dark brown, scapus ventrally brownish yellow. Head black except palpi and mandible yellowish, mandibular teeth dark brown. Mesosoma black except tegula light reddish brown. Metasoma rusty reddish except basal 0.4 of first tergite black and extreme base of second tergite very narrowly blackish; ovipositor sheath blackish. Wings weakly infuscate, wing veins and pterostigma brown. All legs, including coxae, reddish to rusty reddish, except middle and hind tibiae dorsally brownish, basal 0.2 of hind tibia dark brown, middle and hind tarsi brown.

Male. Unknown.

\section{Distribution. Tanzania.}

Etymology. The specific epithet erythrina is the feminine form of the Latinised Greek adjective erythrinus, $-a$, -um meaning reddish; it refers to the colouration of legs and metasoma of the new species.

Remarks. The new species is most similar to Venturia crassicaput (Morley, 1926), which species could be easily distinguished from the new species by its almost entirely black middle and hind coxae, dorsally less darkened hind tibia, more extensively blackish basal tergites of metasoma, more elongate area superomedia ( $\mathrm{Ca} 2 \times$ as long as wide), and distinctly longer ovipositor sheath (almost $3 \times$ as long as hind tibia).

\section{Venturia ignea sp. nov.}

(Figures 7-9)

Material examined. Holotype: female, Ghana, Ashanti region, Kumasi, 293m, 4.II.1968, leg. S. Endrődy-Younga, light trap, No. 297; specimen card-mounted, Id. No. HNHM-HYM 154980. Paratype: female, same locality, date, collector; antennae damaged, specimen card-mounted, Id. No. HNHM-HYM 154981. - The holotype and paratype specimens are deposited in HNHM (Budapest).

Diagnosis. Among the Afrotropical species of the genus, Venturia ignea sp. nov. could be reliably identified by the combined presence of the following characters: gena moderately long, in dorsal view $0.55 \times$ as long as eye width, weakly narrowed behind eye, area superomedia rather elongate and narrow, $c a 3 \times$ as long as wide, with weak, mostly transverse rugosity, area petiolaris irregularly rugose-punctate without transverse wrinkles, propodeal carinae partly weakened, ovipositor sheath $1.3-1.4 \times$ as long as hind tibia, apical half of ovipositor evenly, strongly upcurved, scapus and pedicellus ventrally yellow, mandible yellow except teeth, tegula yellowish, metasoma amber-coloured except petiolus, basal half of second tergite and basal quarter of third tergite black to dark brown, fore and middle legs predominantly yellowish, base of coxae narrowly darkened, femora and ventral side of tibiae with light orange tinge, hind coxa almost entirely dark, trochanter, trochantellus and dorsal side of tibia yellowish, femur, ventral side of tibia and tarsus light orange.

Description. Female (Figs 7-9). Body length ca $8 \mathrm{~mm}$, fore wing length $c a 5 \mathrm{~mm}$.

Head. Antenna with 45 flagellomeres; first flagellomere $c a 3 \times$ as long as wide apically; preapical flagellomeres longer than wide. Head transverse, matt, with dense, relatively long, silvery hairs. Ocular-ocellar distance about as long as ocellus diameter, posterior ocellar distance $1.6-1.7 \times$ as long as ocellus diameter, posterior ocellar distance $1.6-1.7 \times$ as long as ocularocellar distance. Inner eye orbits slightly indented, subparallel. Gena granulate with dense, superficial punctures, moderately long, in dorsal view $0.55 \times$ as long as eye width, weakly narrowed behind eye. Occipital carina complete, medially evenly arched, reaching hypostomal carina little before base of mandible, hypostomal carina not elevated. Frons flat, without median longitudinal carina, rugose-punctate. Face weakly convex in profile, rugose-punctate, punctures moderately strong. Clypeus rugose-punctate, very weakly separated from face, almost flat in profile, relatively wide, its apical margin sharp, medially straight, truncate, laterally very weakly convex. Malar space short, $0.4 \times$ as long as basal width of mandible. Mandible relatively long and strong, lower margin of mandible with a moderately wide flange from base toward teeth, flange gradually 
narrowed toward teeth, mandibular teeth of equal length.

Mesosoma. Mesosoma with dense, short, silvery hairs. Pronotum rugose-punctate, ventral third with weak, short transverse wrinkles; epomia weak. Mesoscutum rugose-punctate, convex in profile, $1.1 \times$ as long as wide, notaulus not developed. Scuto-scutellar groove wide, moderately deep. Scutellum rugose-punctate, convex, lateral carina indistinct. Upper half of mesopleuron weakly rugose with dense punctures, lower half densely punctate on granulate background, distances between punctures smaller than puncture diameters, with rather weak and short transverse wrinkles anterior to speculum; speculum very finely granulate, subpolished, ventrally smooth; mesopleural suture impressed with short, indistinct transverse costae. Epicnemial carina complete, strong, pleural part bent to anterior margin of mesopleuron reaching it below its middle height, transversal part (i.e. part at the level of sternaulus running through the epicnemium to the ventral edge of pronotum) not developed, ventral part (behind fore coxae) complete, not elevated. Sternaulus indistinct. Posterior transverse carina of mesosternum complete. Metanotum rugose-punctate, $c a \quad 0.4 \times$ as long as scutellum. Metapleuron rugose-punctate; juxtacoxal carina indistinct; submetapleural carina complete, strong. Pleural carina of propodeum strong; propodeal spiracle elongate oval, almost touching pleural carina. Propodeum long, its apex reaching middle length of hind coxa, coarsely, irregularly rugose-punctate except area superomedia with weak, mostly transverse rugosity; area petiolaris irregularly rugose-punctate without transverse wrinkles or transverse rugosity, medially not impressed. Area basalis triangular, narrow, longer than its basal width; area superomedia rather elongate and narrow, $\mathrm{ca} 3 \times$ as long as wide, reaching up to basal $0.5 \times$ length of propodeum, apically opened, confluent with area petiolaris; area petiolaris moderately narrow. Propodeal carinae partly weakened; lateromedian longitudinal carinae behind costulae weak; lateral longitudinal carinae obsolescent. Fore wing with short-stalked, relatively large areolet, its stalk $c a$ $0.4 \times$ as long as maximum height of areolet, $3 r s-m$ present, pigmented, second recurrent vein $(2 m-c u)$ distinctly distal to middle of areolet; distal abscissa of $R s$ almost straight, distally weakly curved toward wing margin; nervulus $(c u-a)$ interstitial, weakly inclivous; postnervulus (abscissa of $\mathrm{Cu} 1$ between $1 m-c u$ and $C u 1 \mathrm{a}+\mathrm{Cu} 1 \mathrm{~b}$ ) intercepted at about its middle by $\mathrm{Cu} 1 \mathrm{a}$; lower external angle of second discal cell weakly acute. Hind wing with nervellus ( $c u-a+$ abscissa of $C u 1$ between $M$ and $c u-a$ ) broken, intercepted by discoidella (distal abscissa of $C u 1$ ) at about posterior $0.4 \times$ its length, vertical above discoidella, strongly reclivous below discoidella; discoidella spectral, proximally connected to nervellus. Coxae granulate with weak punctures. Hind femur stout, $c a 4.6 \times$ as long as high. Inner spur of hind tibia $c a 0.5 \times$ as long as first tarsomere of hind tarsus. Tarsal claws slightly longer than arolium, basal half with strong pecten.

Metasoma. Metasoma with short, whitish hairs, compressed, petiolus smooth, from postpetiolus finely granulate to shagreened. First tergite $c a 4.5-4.7 \times$ as long as width of its apical margin, $1.0-1.1 \times$ as long as second tergite, about as long as hind femur, without glymma; dorsomedian carina of first tergite missing; postpetiolus bulging. Suture separating first tergite from first sternite situated little above mid-height at basal third of first metasomal segment. Second tergite long and slender, $c a 2.2-2.4 \times$ as long as its apical width; thyridium small, oval, its distance from basal margin of tergite $c a 4 \times$ as long as its length, not connected to basal margin of tergite by a groove. Posterior margins of apical tergites medially slightly and widely excised. Ovipositor sheath $1.3-1.4 \times$ as long as hind tibia; ovipositor compressed, apical half evenly, strongly upcurved.

Colour. Antenna yellowish brown, dorsally brown, scapus and pedicellus ventrally yellow. Head black except palpi and mandible yellow, mandibular teeth dark brown. Mesosoma black except tegula yellowish. Metasoma amber-coloured except petiolus, basal half of second tergite and basal quarter of third tergite black to dark brown; ovipositor sheath dark brown. Wings hyaline, wing veins and pterostigma brown. Fore and middle legs: coxae pale yellow, basal third to 
half brownish; trochanters and trochantelli pale yellow; femora and ventral side of tibiae yellowish with light orange tinge, dorsal side of tibiae and tarsi yellowish. Hind leg: coxa blackish to dark brown, apically narrowly yellowish; trochanter and trochantellus pale yellow; femur, ventral side of tibia and tarsus light orange, dorsal side of tibia yellowish.

Male. Unknown.

\section{Distribution. Ghana.}

Etymology. The specific epithet ignea is the feminine form of the Latin adjective igneus, $-a$, -um meaning fiery, inflamed, glowing; it refers to the colouration of metasoma and legs of the new species.

Remarks. The new species is somewhat similar to Venturia jordanae Fitton, 1994, which species could be readily distinguished from the new spe- cies by its buccate, distinctly longer gena (in dorsal view $c a 0.9 \times$ as long as eye width), transversely striated area petiolaris and area superomedia, shorter and less upcurved ovipositor (ovipositor sheath as long as hind tibia), and distinctly darker coloured hind legs and metasoma.

\section{Venturia peringueyi (Cameron, 1906)}

Material examined. One male, S. Afr. [= South Africa], Cape Prov., Cape Peninsula, Hout Bay, Skoorsteenkop, 14.II.[19]51, leg. Brinck \& Rudenbeck, Swedish South African Expedition 1950-1951, No. 183, Insect trap, Id. No. MZLUHYM 26392. - One male, same locality, collectors, 2.II.[19]51, No. 166, Id. No. MZLUHYM 26400. - Specimen MZLU-HYM 26392 is deposited in MZLU (Lund), specimen MZLUHYM 26400 is deposited in HNHM (Budapest) (HNHM-HYM 154988).
7.

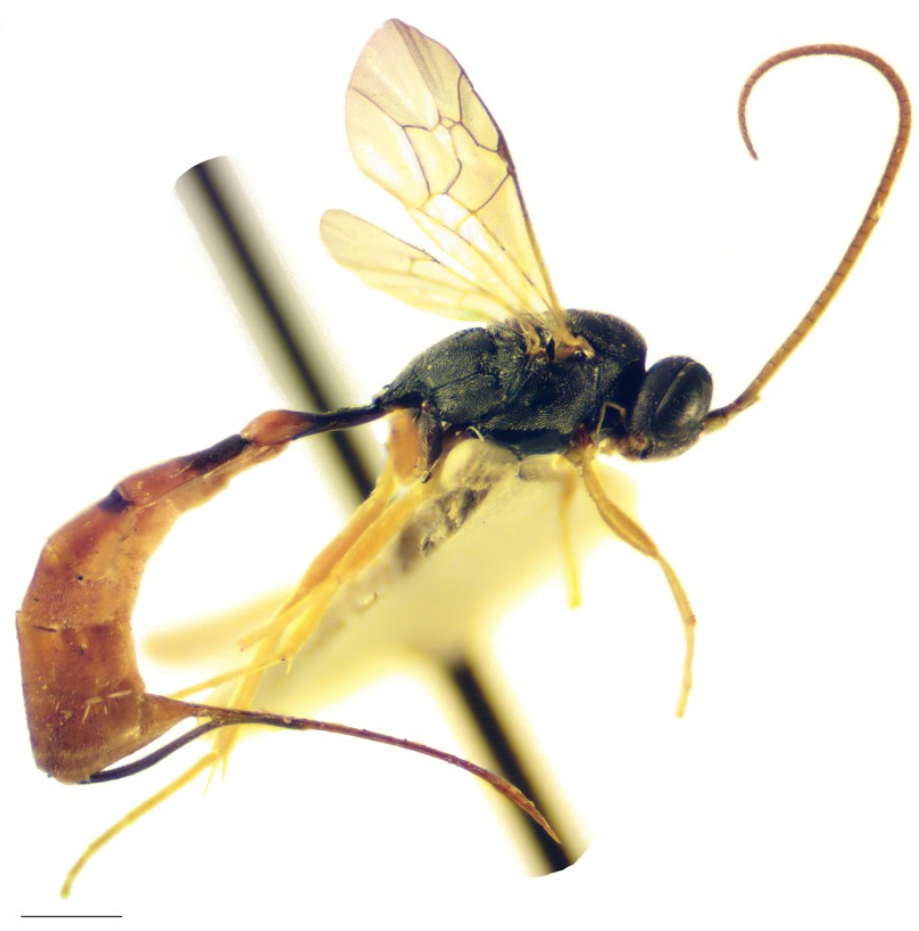

8.

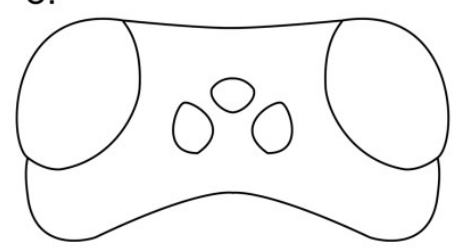

9.

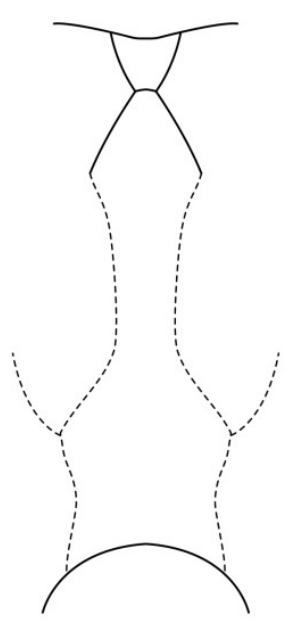

Figures 7-9. Venturia ignea sp. nov. $1=$ holotype, lateral habitus (scale bar $=1 \mathrm{~mm}) ; 2=$ head, dorsal view; $3=$ shape of median areas of propodeum. 
First description of male sex. This species, as well as its junior synonym Venturia areolata (Cameron, 1926), was described from South Africa, based on female sex only (Cameron 1906). The male is similar to the female except in the following characters: antenna with 35-36 flagellomeres; gena little longer than in female, in dorsal view $0.55-0.60 \times$ as long as eye width, less strongly narrowed behind eye; mesopleuron more strongly punctate; propodeal carination and sculpture stronger; area superomedia and area petiolaris little narrower; claspers widely, moderately deeply notched dorsally; metasoma distinctly darker coloured than in female, petiolus dark brown, postpetiolus reddish brown, second and third tergites entirely, fourth tergite basally brownish with weak reddish brown tinge, following tergites dark brown.

\section{Venturia veruta sp. nov.}

(Figures 10-12)

Material examined. Holotype: female, Uganda, Mujenje, VIII.1913, leg. [K.] Katona $[=\mathrm{K}$. Kittenberger]; specimen card-mounted, Id. No. HNHM-HYM 154973. - The holotype specimen is deposited in HNHM (Budapest).

Diagnosis. Among the Afrotropical species of the genus, Venturia veruta sp. nov. could be reliably identified by the combined presence of the following characters: gena moderately long, in dorsal view $0.55 \times$ as long as eye width, weakly narrowed behind eye, area superomedia elongate, narrow, $c a 2 \times$ as long as wide, propodeal carinae partly developed, partly obsolescent, ovipositor sheath $2.9 \times$ as long as hind tibia, ovipositor straight, its apex very weakly sinuous, scapus and pedicellus ventrally narrowly yellowish brown, mandible yellow except teeth, tegula pale yellow, metasoma light amber-coloured except petiolus blackish, postpetiolus basally yellowish brown, basal two-third of second tergite and extreme base of third tergite dark brown, fore and middle legs, except coxae, yellowish, middle and hind coxae almost entirely dark, hind femur and tibia brownish yellow, tibia dorsally brownish.
Description. Female (Figs 10-12). Body length $c a 8 \mathrm{~mm}$, fore wing length $c a 5 \mathrm{~mm}$.

Head. Antenna with 43 flagellomeres; first flagellomere $c a 3 \times$ as long as wide apically; preapical flagellomeres little longer than wide. Head transverse, matt, with dense, relatively long, greyish hairs. Ocular-ocellar distance about as long as ocellus diameter, posterior ocellar distance $1.4 \times$ as long as ocellus diameter, posterior ocellar distance $1.4 \times$ as long as ocular-ocellar distance. Inner eye orbits slightly indented, subparallel. Gena granulate with weak punctures, moderately long, in dorsal view $0.55 \times$ as long as eye width, weakly narrowed behind eye. Occipital carina complete, medially evenly arched, reaching hypostomal carina little before base of mandible, hypostomal carina not elevated. Frons flat, without median longitudinal carina, rugose-punctate, punctures weaker than on face and clypeus. Face flat in profile, rugose-punctate, punctures moderately strong. Clypeus rugose-punctate, very weakly separated from face, flat in profile, relatively wide, its apical margin sharp, medially straight, truncate, laterally weakly convex. Malar space short, $0.5 \times$ as long as basal width of mandible. Mandible relatively long and strong, lower margin of mandible with a rather narrow flange from base toward teeth, flange gradually narrowed toward teeth, upper mandibular tooth little longer than lower tooth.

Mesosoma. Mesosoma with dense, moderately short, silvery hairs. Pronotum rugose-punctate, ventral half with weak transverse wrinkles; epomia weak. Mesoscutum rugose-punctate, convex in profile, little longer than wide, notaulus not developed. Scuto-scutellar groove wide, relatively shallow. Scutellum rugose-punctate, convex, lateral carina indistinct. Upper half of mesopleuron moderately rugose with dense punctures, lower half densely punctate on coarsely granulate background, distances between punctures smaller than puncture diameters, with rather weak transverse wrinkles anterior to speculum; speculum relatively small, very finely granulate, subpolished; mesopleural suture impressed with short, weak transverse costae. Epicnemial carina complete, strong, pleural part bent to anterior margin of mesopleuron reaching it below its middle height, 
transversal part (i.e. part at the level of sternaulus running through the epicnemium to the ventral edge of pronotum) not developed, ventral part (behind fore coxae) complete, not elevated. Sternaulus indistinct. Posterior transverse carina of mesosternum complete, slightly elevated, medially not excised. Metanotum rugose-punctate, $c a$ $0.5 \times$ as long as scutellum. Metapleuron granulate to rugose with dense punctures; juxtacoxal carina indistinct; submetapleural carina complete, strong. Pleural carina of propodeum moderately strong; propodeal spiracle oval, separated from pleural carina by $\mathrm{ca} 0.5 \times$ its length. Propodeum long, its apex reaching little beyond middle length of hind coxa, coarsely rugose-punctate except area superomedia granulate with weak transverse wrinkles and area petiolaris granulate to rugose with relatively weak transverse wrinkles, medially not impressed. Area basalis triangular, small, about as long as its basal width; area superomedia elongate, narrow, $c a 2 \times$ as long as wide, reaching almost up to basal $0.5 \times$ length of propodeum, apically opened, confluent with area petiolaris; area petiolaris narrow. Propodeal carinae partly developed; lateromedian longitudinal carinae developed before costulae but relatively weak, behind costulae obsolescent; costulae developed but relatively weak; lateral longitudinal carinae obsolescent; posterior transverse carina only laterally developed. Fore wing with short-stalked, relatively large areolet, its stalk $c a \quad 0.4 \times$ as long as maximum height of areolet, 3rs-m present, pigmented, second recurrent vein $(2 m-c u)$ little distal to middle of areolet; distal abscissa of $R s$ almost straight, distally weakly curved toward wing margin; nervulus $(\mathrm{cu}-a)$ interstitial, distinctly inclivous; postnervulus (abscissa of $\mathrm{Cu} 1$ between $1 \mathrm{~m}-\mathrm{cu}$ and $\mathrm{Cu} 1 \mathrm{a}+\mathrm{Cu} 1 \mathrm{~b}$ ) intercepted slightly below its middle by $C u 1 \mathrm{a}$; lower external angle of second discal cell acute. Hind wing with nervellus (cu- $a+$ abscissa of $C u 1$ between $M$ and $c u-a$ ) broken, intercepted by discoidella (distal abscissa of $\mathrm{Cu} 1$ ) at about posterior $0.25 \times$ its length, vertical above discoidella, reclivous below discoidella; discoidella spectral, proximally connected to nervellus. Coxae granulate with weak punctures. Hind femur relatively stout, $c a 5 \times$ as long as high. Inner spur of hind tibia $c a 0.5 \times$ as long as first tarsomere of hind tarsus. Tarsal claws little longer than arolium, basal half with distinct pecten.

Metasoma. Metasoma with moderately short, whitish hairs, compressed, petiolus smooth, from postpetiolus finely granulate to shagreened. First tergite $c a 5 \times$ as long as width of its apical margin, $0.9 \times$ as long as second tergite, as long as hind femur, without glymma; dorsomedian carina of first tergite missing; postpetiolus bulging. Suture separating first tergite from first sternite situated slightly above mid-height at basal third of first metasomal segment. Second tergite rather long and slender, $c a 2.7 \times$ as long as its apical width; thyridium small, rather weak, subcircular, its distance from basal margin of tergite $\mathrm{ca} 3.5 \times$ as long as its length, not connected to basal margin of tergite by a groove. Posterior margins of third and following tergites medially slightly and widely concave, apical tergites more strongly excised medially. Ovipositor sheath $2.9 \times$ as long as hind tibia; ovipositor compressed, straight, its apex very weakly sinuous, dorsal preapical notch weak, indistinct.

Colour. Antenna brown, scapus and pedicellus ventrally narrowly yellowish brown. Head black except palpi and mandible yellow, mandibular teeth dark brown. Mesosoma black except tegula pale yellow. Metasoma light amber-coloured except petiolus blackish, postpetiolus basally yellowish brown, basal two-third of second tergite and extreme base of third tergite dark brown; ovipositor sheath blackish. Wings subhyaline, wing veins and pterostigma brown. Fore leg: coxa basally brownish, apically yellowish; trochanter, trochantellus, femur, tibia and tarsus yellowish. Middle leg: coxa dark brown, apically narrowly yellowish; trochanter, trochantellus, femur, tibia and tarsus yellowish, apical tarsomere brownish. Hind leg: coxa blackish to dark brown, apically very narrowly yellowish; trochanter brownish, apically yellowish; trochantellus yellowish; femur brownish yellow; tibia brownish yellow, dorsally brownish; tarsus brownish.

Male. Unknown.

Distribution. Uganda. 

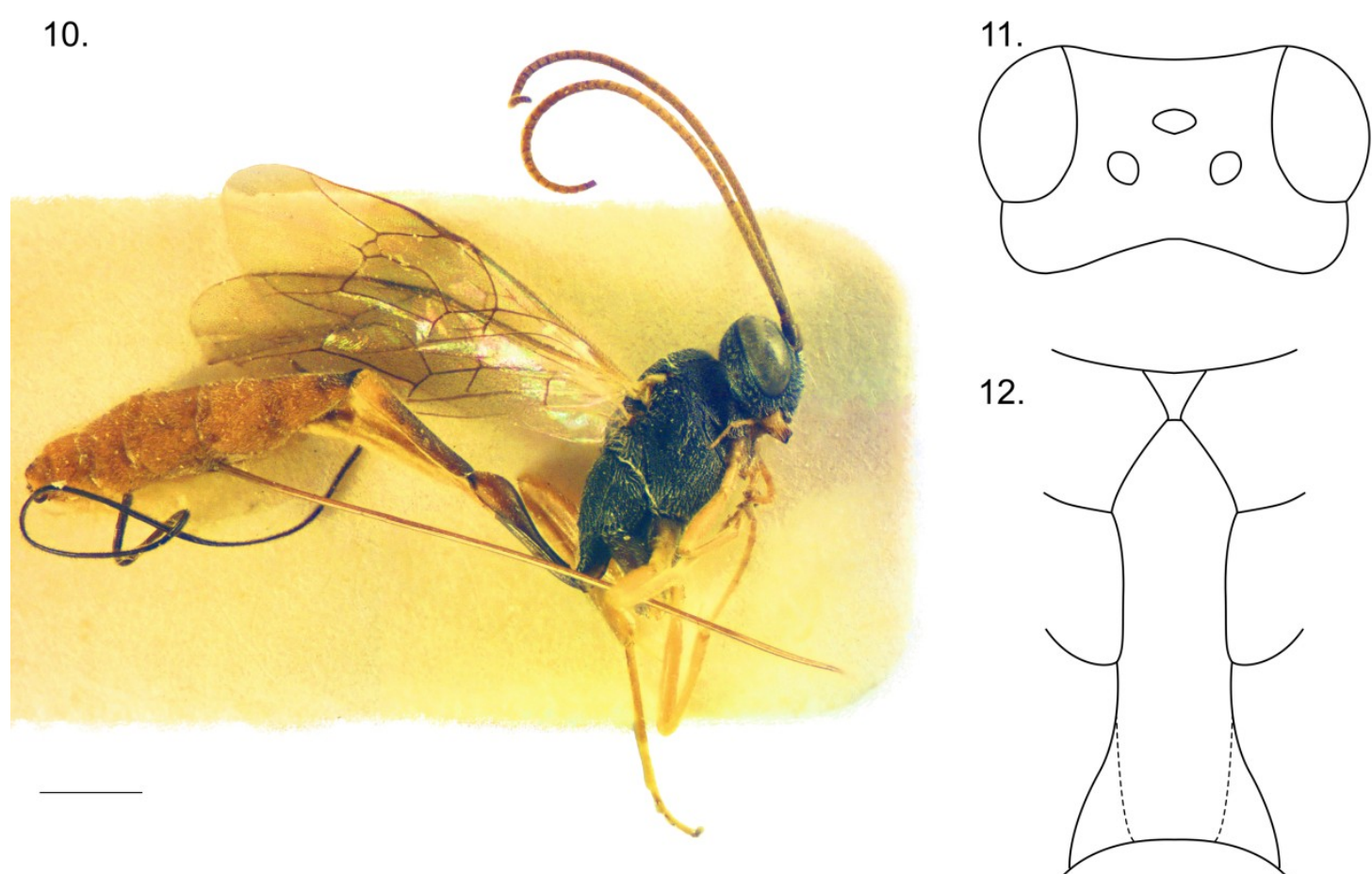

12.

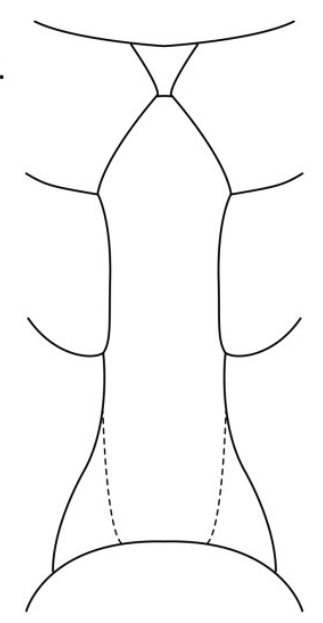

Figures 10-12. Venturia veruta sp. nov. $1=$ holotype, lateral habitus $($ scale bar $=1 \mathrm{~mm}) ; 2=$ head, dorsal view; $3=$ shape of median areas of propodeum.

Etymology. The specific epithet veruta is the feminine form of the Latin adjective verutus, $-a$, um meaning armed with a javelin; it refers to the long and straight ovipositor of the new species.

Remarks. The new species has a rather unique character combination, which is dissimilar to any known Venturia species in the region (see Diagnosis section). Due to the very long ovipositor it is rather superficially similar to Venturia crassicaput (Morley, 1926), which species could be readily distinguished from the new species by its buccate, distinctly longer gena (in dorsal view $c a$ $0.7 \times$ as long as eye width), stronger propodeal carination, strongly upcurved ovipositor tip, and predominantly reddish colouration of legs and metasoma.

\section{ORIENTAL REGION}

Before this study, 35 valid species were known from the region ( $\mathrm{Yu}$ et al. 2012). Gupta \&
Maheshwary (1977) revised the Oriental species; since then only four species were described from the region (Kusigemati 1988, Sudheer \& Narendran 2006). With the new species described below, the number of Oriental Venturia species increased to 36 .

\section{Venturia biroi sp. nov.}

(Figures 13-15)

Material examined. Holotype: female, India or. [ $=$ orientalis], [Maharastra state], Matheran, 10.VII.1902, leg. [L.] Bíró; specimen pinned, Id. No. HNHM-HYM 154967. - The holotype specimen is deposited in HNHM (Budapest).

Diagnosis. Among the Oriental species of the genus, Venturia biroi sp. nov. could be reliably identified by the combined presence of the following characters: antennal flagellomeres dark brown, scapus and pedicellus almost entirely pale yellow except a narrow brown stripe laterally, 
frons without median longitudinal carina, face rugose-punctate, posterior ocellar distance $2.5 \times$ as long as ocular-ocellar distance, mandible pale yellow, its lower margin with rather wide flange, gradually narrowed toward teeth, tegula pale yellow, mesopleuron and metapleuron strongly, densely punctate on smooth background, area superomedia elongate hexagonal, moderately narrow, $1.6 \times$ as long as wide, almost entirely smooth, area petiolaris with strong transverse wrinkles, fore wing with petiolate, long-stalked, small areolet, nervellus intercepted, ovipositor sheath $1.5 \times$ as long as hind tibia, first tergite black, apically brownish, second and third tergites blackish, apically narrowly reddish brown, following tergites dorsally blackish, laterally reddish brown, hind femur reddish brown, hind tibia reddish brown, subbasally and apically darkened, basal yellowish brown spot present but indistinct.

Description. Female (Figs 13-15). Body length $c a 7 \mathrm{~mm}$, fore wing length $c a 4 \mathrm{~mm}$.

Head. Antenna with 33 flagellomeres; first flagellomere long and slender, $c a 4 \times$ as long as wide apically; preapical flagellomeres quadrate to slightly longer than wide. Head transverse, matt, with dense, greyish hairs. Ocular-ocellar distance $0.6 \times$ as long as ocellus diameter, posterior ocellar distance $1.5 \times$ as long as ocellus diameter, posterior ocellar distance $2.5 \times$ as long as ocular-ocellar distance. Inner eye orbits slightly indented, parallel. Gena granulate with weak punctures, short, in dorsal view $0.3 \times$ as long as eye width, strongly narrowed behind eye. Occipital carina complete, medially evenly arched, reaching hypostomal carina little before base of mandible, hypostomal carina little elevated. Frons flat, without median longitudinal carina, rugose-punctate, punctures weaker than on face and clypeus. Face weakly convex in profile, strongly rugose-punctate. Clypeus strongly rugose-punctate, very weakly separated from face, almost flat in profile, relatively wide, its apical margin weakly convex, sharp. Malar space short, $0.4 \times$ as long as basal width of mandible. Mandible relatively long, lower margin of mandible with rather wide flange from base toward teeth, flange gradually nar- rowed toward teeth, mandibular teeth of equal length.

Mesosoma. Mesosoma with dense, short, greyish hairs. Dorsal third of pronotum rugosepunctate, ventral two-third smooth with strong transverse wrinkles; epomia weak. Mesoscutum coarsely rugose-punctate, convex in profile, about as long as wide, notaulus not developed. Scutoscutellar groove wide, relatively shallow. Scutellum punctate, apically rugose-punctate, convex, lateral carina indistinct. Mesopleuron strongly, densely punctate on smooth, shiny background, distances between punctures smaller than puncture diameters, with relatively long and strong transverse wrinkles anterior to speculum; speculum large, smooth, shiny; mesopleural suture impressed with short, weak transverse costae. Epicnemial carina complete, strong, pleural part bent to anterior margin of mesopleuron reaching it below its middle height, transversal part (i.e. part at the level of sternaulus running through the epicnemium to the ventral edge of pronotum) not developed, ventral part (behind fore coxae) complete, slightly elevated. Sternaulus indistinct. Posterior transverse carina of mesosternum complete, little elevated, medially not excised. Metanotum rugose-punctate, $c a 0.4 \times$ as long as scutellum. Metapleuron strongly, densely punctate on smooth background; juxtacoxal carina indistinct; submetapleural carina complete, strong. Pleural carina of propodeum strong; propodeal spiracle elongate oval, separated from pleural carina by about its length, connected to pleural carina by a distinct ridge. Propodeum long, its apex reaching middle length of hind coxa, coarsely rugose-punctate except area superomedia almost entirely smooth and area petiolaris with strong transverse wrinkles, medially not impressed. Area basalis trapezoidal, shorter than its basal width; area superomedia elongate hexagonal, moderately narrow, $1.6 \times$ as long as wide, reaching up to basal $0.3 \times$ length of propodeum; area petiolaris moderately wide. Propodeal carinae strongly developed, area superomedia apically opened, confluent with area petiolaris. Fore wing with petiolate, long-stalked, small areolet, its stalk about as long as maximum height of areolet, $3 r s-m$ present, pigmented, second recurrent vein $(2 m-c u)$ very 
close to distal corner of areolet; distal abscissa of $R s$ straight; nervulus ( $c u-a$ ) interstitial; postnervulus (abscissa of $C u 1$ between $1 \mathrm{~m}-\mathrm{cu}$ and $\mathrm{Cu} 1 \mathrm{a}+$ $\mathrm{Cu} 1 \mathrm{~b}$ ) intercepted little above its middle by $\mathrm{Cu}$ a; lower external angle of second discal cell acute. Hind wing with nervellus (cu- $a+$ abscissa of $C u 1$ between $M$ and $c u-a$ ) broken, intercepted by discoidella (distal abscissa of $C u 1$ ) at about posterior $0.35 \times$ its length, vertical above discoidella, weakly reclivous below discoidella; discoidella spectral, proximally connected to nervellus. Coxae granulate with distinct punctures. Hind femur relatively stout, $c a 5 \times$ as long as high. Inner spur of hind tibia $c a 0.5 \times$ as long as first tarsomere of hind tarsus. Tarsal claws thin, little longer than arolium, basal half with small but distinct pecten.

Metasoma. Metasoma with short, greyish hairs, compressed, petiolus smooth, from postpetiolus finely granulate to shagreened. First tergite $c a 4.2 \times$ as long as width of its apical margin, $1.15 \times$ as long as second tergite, $0.95 \times$ as long as hind femur, without glymma; dorsomedian carina of first tergite missing; postpetiolus bulging. Suture separating first tergite from first sternite situated little above mid-height at basal third of first metasomal segment. Second tergite long and slender, $c a 2.3 \times$ as long as its apical width; thyridium small, oval, its distance from basal margin of tergite $c a 3 \times$ as long as its length, connected to basal margin of tergite by a weak, almost indiscernibly shallow groove. Posterior margins of third and following tergites medially slightly and widely concave. Ovipositor sheath $1.5 \times$ as long as hind tibia and $1.9 \times$ as long as hind femur (total length of exposed ovipositor $1.8 \times$ as long as hind tibia and $2.2 \times$ as long as hind femur); ovipositor compressed, weakly upcurved.

Colour. Antennal flagellomeres dark brown, scapus and pedicellus almost entirely pale yellow except a narrow brown stripe laterally. Head black except palpi and mandible pale yellow, mandibular teeth reddish brown. Mesosoma black except tegula pale yellow. Metasoma: petiolus black, postpetiolus black, apically brownish; second and third tergites blackish, apically narrowly reddish brown; following tergites dorsally blackish, laterally reddish brown; ovipositor sheath blackish. Wings hyaline, wing veins and pterostigma brown. Fore leg: coxa dark brown, apical third yellowish; trochanter and trochantellus pale yellow; femur, tibia and tarsus yellowish brown, apical tarsomere brownish. Middle leg: coxa blackish to dark brown, apically narrowly yellowish; trochanter and trochantellus pale yellow; femur, tibia and tarsus yellowish brown, apical tarsomere brownish. Hind leg: coxa black, apically narrowly yellowish; trochanter and trochantellus pale yellow; femur reddish brown; tibia reddish brown, subbasally and apically darkened, basal yellowish brown spot present but rather indistinct; tarsus brown except extreme base of first tarsomere very narrowly yellowish brown.

Male. Unknown.

\section{Distribution. India.}

Etymology. This species is dedicated to the memory of its collector, Lajos Bíró (1856-1931), in honour of his exceedingly remarkable collecting activity and work for the Hungarian natural history collection, and especially for the Hymenoptera Collection.

Remarks. By using the identification key in Gupta \& Maheshwary (1977), the new species key out with Venturia palmaris (Wilkinson, 1928) at couplet 14, but without complete match to the characters given in the couplet. Venturia palmaris (Wilkinson, 1928) could be distinguished from the new species by its following characteristics: posterior ocellar distance $1.8 \times$ as long as ocularocellar distance, frons with median longitudinal carina, area superomedia with weak transverse striae, total length of exposed ovipositor significantly longer ( $3 \times$ as long as hind femur), scapus and pedicellus only ventrally yellowish. The new species is also somewhat similar to Venturia girishi Sudheer et Narendran, 2006, which species could be easily distinguished from the new species by its not intercepted nervellus and distinctly shorter ovipositor sheath $(1.6 \times$ as long as hind femur), and colouration differences of scapus, pedicellus, legs and metasoma. Venturia canescens (Gravenhorst, 1829) could also be readily distinguished from the new species by its large, 
13.

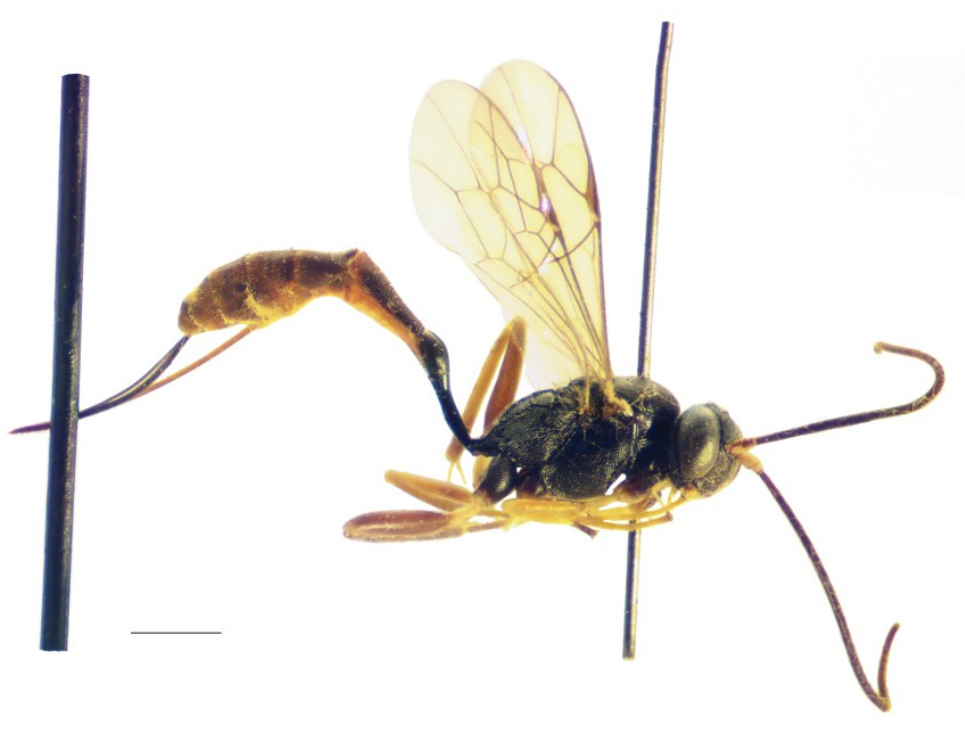

14.

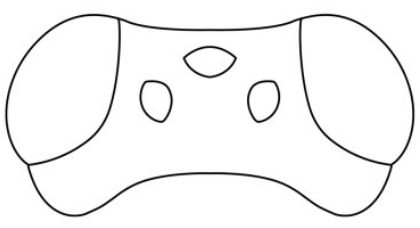

15.

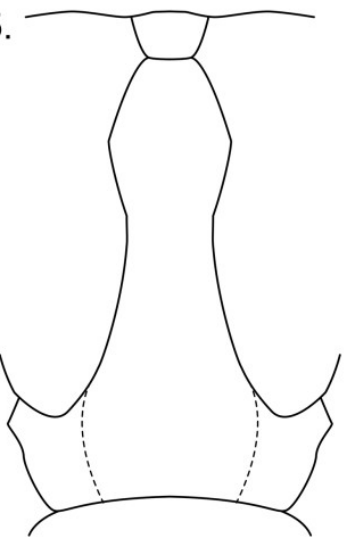

Figures 13-15. Venturia biroi sp. nov. $1=$ holotype, lateral habitus $($ scale bar $=1 \mathrm{~mm}) ; 2=$ head, dorsal view; $3=$ shape of median areas of propodeum.

sessile or subsessile areolet, significantly longer, narrower and more strongly sculptured area superomedia, and colouration differences of scapus, pedicellus, legs and metasoma.

\section{PALAEARCTIC REGION}

Eight valid species are known from the region (Yu et al. 2012). An identification key to the Western Palaearctic species was given by Vas (2019a).

\section{Venturia canescens (Gravenhorst, 1829)}

Material examined. Two females, Cyprus, Larnaka, VI.1900, leg. Glaszner, Id. No. HNHMHYM 154962, 154963. - One female, [Greece], Creta $[=$ Crete $]$, Herakelion $[=$ Heraklion $]$, V.1906, leg. [L.] Bíró, Id. No. MZLU-HYM 154961. - The specimens are deposited in HNHM (Budapest).
Remarks. First records for Cyprus and Crete. This species has a worldwide distribution ( $\mathrm{Yu}$ et al. 2012, Vas 2019a).

Acknowledgements - I am grateful to Rune Bygebjerg (Biological Museum, Lund) for the opportunity to borrow and study unidentified specimens from the collection of Biological Museum, Lund University. I thank Marin Husemann (Zoological Museum, Hamburg) for his efforts in locating relevant type material. The author was supported by the Hungarian Government, Ministry of Human Capacities (Emberi Erőforrások Minisztériuma) in the frame of the NTP-NFTÖ-19-B-0007 scholarship (Nemzet Fiatal Tehetségeiért Ösztöndíj).

\section{REFERENCES}

CAmeron, P. (1906): Descriptions of new species of parasitic Hymenoptera chiefly in the collection of the South African Museum, Cape Town. Annals of the South African Museum, 5: 17-186.

CAMERON, P. (1912): On the Hymenoptera from Belgian Congo in the Congo Museum, Tervueren. 
Annales de la Société Entomologique de Belgique, 56: 357-401.

ENDERLEIN, G. (1914): Hymenoptera IV: Ichneumonidae. In. MICHAELSEN W. (Ed.) Beiträge zur Kenntnis der Land-und Süsswasserfauna DeutschSüdwestafrikas. Band 1. Hamburg, p. 211-233.

FÖRSTER, A. (1869): Synopsis der Familien und Gattungen der Ichneumonen. Verhandlungen des Naturhistorischen Vereins der Preussischen Rheinlande und Westfalens, 25(1868): 135-221.

GAULD, I.D. (1991): The Ichneumonidae of Costa Rica, 1. Introduction, keys to subfamilies, and keys to the species of the lower Pimpliform subfamilies Rhyssinae, Poemeniinae, Acaenitinae and Cylloceriinae. Memoirs of the American Entomological Institute, 47: 1-589.

Gauld, I.D., Wahl, D., BRADShaW, K., Hanson, P. \& WARD, S. (1997): The Ichneumonidae of Costa Rica, 2. Introduction and keys to species of the smaller subfamilies, Anomaloninae, Ctenopelmatinae, Diplazontinae, Lycorininae, Phrudinae, Tryphoninae (excluding Netelia) and Xoridinae, with an appendix on the Rhyssinae. Memoirs of the American Entomological Institute, 57: 1-485.

GRAVENHORST, J.L.C. (1829): Ichneumonologia Europaea. Pars III. Vratislaviae, 1097 pp. doi: 10.5962/bhl.title. 65750

GUPTA, V.K. \& MAHESHWARY, S. (1977): Ichneumonologia Orientalis, Part IV. The tribe Porozontini (=Campoplegini) (Hymenoptera: Ichneumonidae). Oriental Insects Monograph, 5: 1-267.

HorstmanN, K. (1973): Übersicht über die europäischen Arten der Gattung Venturia Schrottky (Hymenoptera, Ichneumonidae). Mitteilungen der Deutschen Entomologischen Gesellschaft, 32: 7-12.

HORSTMANN, K. (1979): Revision der von Kokujev beschriebenen Campopleginae-Arten (mit Teiltabellen der Gattungen Venturia Schrottky, Campoletis Förster und Diadegma Förster). Beiträge zur Entomologie, 29: 195-199.

HORSTMANN, K. (2008): Neue westpalaarktische arten der Campopleginae (Hymenoptera: Ichneumonidae). Zeitschrift der Arbeitsgemeinschaft Oesterreichischer Entomologen, 60: 3-27.

JONATHAN, J.K. (1999): Hymenoptera: Ichneumonidae. Fauna of West Bengal. Part. 8. Insecta (Trichoptera, Thysanoptera, Neuroptera, Hymeno- ptera and Anoplura). Zoological Survey of India, Calcutta, 442 pp.

KUSIGEMATI, K. (1988): Descriptions of four new Ichneumon flies parasitic on pine insect pests in Thailand (Hymenoptera: Ichneumonidae). Memoirs of the Faculty of Agriculture, Kagoshima University, 24: 147-155.

Magretti, P. (1884): Roccolte imenotterologiche nell'Africa orientale. Bollettino della Societa Entomologica Italiana, 15: 241-253.

MomoI, S. (1965): Description of a new Ichneumonfly of the genus Devorgilla from Japan (Hymenoptera: Ichneumonidae). Science Reports of the Hyogo University of Agriculture, 7(1): 38.

Morley, C. (1926): On some South African Ichneumonidae in the collection of the South African Museum. Annals of the South African Museum, 23: 435-481.

PolaszeK, A., FitTon, M.G., Bianchi, G. \& HudDLESTON, T. (1994): The parasitoids of the African white rice borer, Maliarpha separatella Ragonot (Lepidoptera: Pyralidae). Bulletin of Entomological Research, 84: 65-89. doi: $\underline{10.1017 / \mathrm{S} 0007485300032247}$

SCHROTTKY, C. (1902): Neue argentinische Hymenoptera. Anales del Museo Nacional de Buenos Aires, 8: 91-117.

SEYRIG, A. (1935): Mission scientifique de l'Omo. Tome III. Fascicule 18. Hymenoptera, II. Ichneumonidae: Cryptinae, Pimplinae, Tryphoninae et Ophioninae. Mémoires du Muséum National d'Histoire Naturelle, 4: 1-100.

SUdHEER, K. \& NARENDRAN, T.C. (2006): Three new species of Venturia Schrottky (Hymenoptera: Ichneumonidae) from India. Oriental Insects, 40: 317-325. doi: $10.1080 / 00305316.2006 .10417485$

TOWNES, H. \& TownEs, M. (1973): A catalogue and reclassification of the Ethiopian Ichneumonidae. Memoirs of the American Entomological Institute, 19: $1-416$.

TOWNES, H. (1969): The genera of Ichneumonidae. Part 1. Memoirs of the American Entomological Institute, 11: 1-300.

TOWNES, H. (1970): The genera of Ichneumonidae. Part 3. Memoirs of the American Entomological Institute, 13: 1-307. 
Townes, H., Townes, M. \& GuPTA, V.K. (1961): A catalogue and reclassification of the Indo-Australian Ichneumonidae. Memoirs of the American Entomological Institute, 1: 1-522.

VAN NOORT, S. (2019): WaspWeb: Hymenoptera of the Afrotropical region. Available from: http:// www.waspweb.org (accessed 15 March 2020)

VAS, Z. (2019a): Contributions to the taxonomy, identification, and biogeography of Casinaria Holmgren and Venturia Schrottky (Hymenoptera: Ichneumonidae: Campopleginae). Zootaxa, 4664(3): 351-364. doi: 10.11646/zootaxa.4664.3.3

VAS, Z. (2019b): New species and new records of Campopleginae from the Palaearctic region (Hymenoptera: Ichneumonidae). Folia entomologica hungarica, 80: 247-271.

VIERECK, H.L. (1914): Type species of the genera of Ichneumon flies. United States National Museum Bulletin, 83: 1-186. doi: 10.5479/si.03629236.83.1
WAHL, D.B. (1987): A revision of Venturia north of Central America (Hymenoptera: Ichneumonidae). University of Kansas, Science Bulletin, 53: 275356.

YU, D.S. \& HoRSTMANN, K. (1997): A catalogue of world Ichneumonidae (Hymenoptera). Memoirs of the American Entomological Institute, 58: 1-1558.

Yu, D.S., van Achterberg, C. \& Horstmann, K. (2012): Taxapad 2012 - World Ichneumonoidea 2011. Taxonomy, Biology, Morphology and Distribution. Ottawa, Ontario, www.taxapad.com.

ZWART, K.W.R. (1998): Ichneumonidae. In. POLASZEK, A. (Ed.) African cereal stem borers: economic importance, taxonomy, natural enemies and control. CAB International, Oxon \& New York, p. $205-258$. 